\title{
O duplo caráter do direito à existência: luta de classes e articulação estrutural das contrarreformas sociais, políticas e ambientais`.
}

\section{The double character of the right of existence: class struggle and structural articulation of social, political and environmental contrarreforms.}

Resumo: O artigo busca, a partir da tradição marxista e desde a sugestão formulada por Daniel Bensaïd, evidenciar o duplo caráter do Direito à Existência, este caracterizado como salvaguarda à reprodução da vida e como mediação à afirmação política das classes trabalhadoras e setores oprimidos da sociedade. Olhando para a contemporânea realidade brasileira, possuindo caráter eminentemente teórico e pautado no método materialista- histórico, demonstra como as contrarreformas direcionadas aos direitos sociais guardam articulação estrutural com os ataques direcionados ao meio ambiente, reclamando contraposição do mesmo modo incisiva dos movimentos sociais na defesa de seus interesses imediatos pela assunção de bandeiras ecológicas.

Palavras-chave: Direito à Existência; direitos sociais e políticos; meio ambiente.

\footnotetext{
- O presente texto é tributário das discussões realizadas nos Grupo de Pesquisa Trabalho e Capital (GPTC-USP), em seu braço de atuação na Universidade Federal de Lavras, bem como das atividades realizadas no Núcleo de Estudos Trabalho, História e Direitos Sociais (NETHDSUFLA), no curso do primeiro semestre de 2017. Daí a necessidade de agradecer a todas e todos que participaram de seus encontros, sendo força coletiva que impulsionou estas reflexões. É de se registrar que estas formulações, agora devidamente atualizadas, foram expostas de forma embrionária em palestra ministrada no "Seminário Reforma Trabalhista e da Previdência Social: crítica jurídica e teoria do valor em Marx", em 7 de junho de 2017, na FD-UFMG, em mesa partilhada com Daniela Muradas (UFMG), Ricardo Antunes (UNICAMP) e Marco Aurélio Serau Júnior (UFPR), contando com mediação de Humberto Marcial Fonseca (DECLATRA). * Professor Adjunto, em regime de dedicação exclusiva, do Departamento de Direito do Trabalho e Introdução ao Estudo do Direito da Universidade Federal de Minas Gerais (DIT-UFMG). Professor do corpo permanente do Programa de Pós-Graduação em Direito da Universidade Federal de Minas Gerais. Doutor em Direito do Trabalho pela FDUSP (2017), orientado por Jorge Luiz Souto Maior, sendo a tese aprovada com louvor e distinção. Titulou-se na mesma instituição mestre em Direito do Trabalho (2012, aprovado com louvor) e bacharel em Direito (2008). Pesquisador convidado, em sede de pós-doutorado, do CéSor/EHESS/CNRS, sob supervisão de Michael Löwy (2018). Foi Professor Adjunto de Direito da Universidade Federal de Lavras - UFLA (2016-2019) e de outras instituições de ensino superior.
} 
Abstract: The article seeks, based on the Marxist tradition and since the suggestion made by Daniel Bensaïd, to highlight the double character of the Right to Existence, this characterized as a safeguard for the reproduction of life and as a mediation for the political affirmation of the working classes and oppressed sectors of society. Looking at the contemporary Brazilian reality, having an eminently theoretical character and based on the materialisthistorical method, it demonstrates how the counter-reforms directed at social rights keep structural articulation with the attacks directed at the environment, claiming the same opposition of social movements in their task by the assumption of ecological flags.

Keywords: Resistance; right of existence; social and political rights; environment.

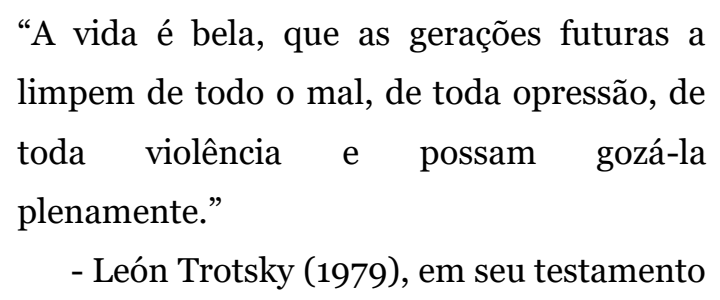

\section{Introdução}

A civilização capitalista, moderna e industrial encontra-se em crise. $\mathrm{O}$ diagnóstico, firmado por Michael Löwy (2013), nunca nos pareceu tão evidente, muito embora os esforços para manutenção de uma aura de normalidade pelos reais interessados na constância do estado de coisas sejam imensos, hercúleos.

Ter em conta que experimentamos uma crise civilizacional importa reconhecer que a bifurcação histórica que nos encontramos não deriva apenas de fatores econômicos, ainda que estes cumpram um forte papel em tal cenário. Trata-se de uma crise que tem dimensões morais, institucionais, políticas e ecológicas marcadas, e que passa, com o violento irromper em 2020 da pandemia da COVID-19, a também se alarmar por sua faceta sanitária.

Estes elementos nos levam a colocar na ordem do dia as discussões acerca das condições de existência humanas no cerne da sociedade capitalista, e o modo como as classes trabalhadoras, bem como o conjunto dos oprimidos e oprimidas da sociedade, se colocam em movimento para salvaguardar suas conquistas históricas e galgar novas e melhores condições de vida. Neste 
contexto, em que os elementos caracterizadores desta crise civilizacional se entrelaçam e determinam mutuamente, passa-se a reclamar de modo urgente um imbricado e complexo processo de enfrentamentos pela parcela da humanidade que se vê mais assolada por seus efeitos.

Esta luta, entendemos, pode ser condensada taticamente desde um desenho estruturante sugerido por Daniel Bensaïd ao reavivar a ideia de um Direito à Existência, proposição que pretendemos desenvolver no presente texto.

Tomando por base concreta para a reflexão a realidade brasileira do último período, com destaque aos processos que resultam e derivam da série de ataques às condições de vida do conjunto de pessoas oprimidas e exploradas que desde 2016 passam a se afigurar de forma mais acelerada, muito embora sinalizadas e conduzidas também em períodos anteriores -, pretendemos lançar proposições teóricas que demonstrem a indispensabilidade de articulação das lutas contra o desmonte de direitos sociais, as formas tradicionais de sociabilidade e a repaginação institucional e econômica de matiz ecocida, tendo em conta o comum interesse tudo com fito recompor as perspectivas de acumulação do capital e reestabelecer as margens de lucro em tempos de crise.

Do próprio título da exposição despontam alguns pontos de necessário enfrentamento, que servirão de guia à nossa exposição, calcada fundamentalmente em revolvimento textual e articulação teórica desde o método materialista-histórico. Esta compreenderá em três partes fundamentais, desembocando em item conclusivo: (i) o trato do Direito à Existência como chave passível de ser defendida a partir de um referencial marxista, guardando particular historicidade e dual compreensão; (ii) o modo como as duas dimensões do Direito à Existência expressam uma unidade dialética inextricável; (iii) a maneira como o conjunto de contrarreformas ${ }^{1}$ sociais $\mathrm{e}$ políticas se combina, na temporalidade e agenda regressivas burguesas, com os

\footnotetext{
${ }^{1}$ Adotamos aqui o termo em tributo à elaboração da professora Andréia Maria de Paula Teixeira (2001, p. 49-62). A construção caminha no sentido por certo não vetorial, mas polarizado na leitura de mundo em classes, de que a perspectiva de disputa por reformas empenha-se na melhoria da proteção social, ampliação da intervenção do Estado no plano econômico para fins minoração de desigualdades, entre outras medidas. Já as contrarreformas se caracterizam pelas inflexões institucionais voltadas à redução da intervenção do Estado nesse campo e ampliação do império do mercado e do interesse privado do lucro no trato da questão social.
} 
ataques ao meio ambiente vivenciados na história recente do país; tudo a apontar a (iv) necessidade de uma articulação do conjunto de movimentos sociais a bandeiras ecológicas aptas a enfrentar a contento a crise civilizacional ora vivenciada.

\section{A luta por direitos e o Direito à Existência}

A tomada inicial do Direito à Existência reclama desde logo a resposta a alguns questionamentos: no que este se caracterizaria? É um direito que serve a todos, com pretensões universais? Pareceria sua defesa, dentro dos marcos da juridicidade, apropriado aos olhos daquelas e daqueles que se propõem a ler o direto a partir do referencial marxista?

O primeiro registro que há de se fazer é que por Direito à Existência compreendemos a perspectiva de garantia da existência material e política das classes trabalhadoras. Condição indispensável para que possam as pessoas que vivem da venda da força de trabalho constituir-se enquanto seres viventes, bem como sujeitos sociais no empenhar de suas tarefas históricas.

Tomamos originalmente - com intuito de conceber e desenvolver nossa formulação - as provocações lançadas por Daniel Bensaïd (1989; 2003; 2007; 2008). O filósofo e militante francês, de forma sintética, tomou a construção do Direito à Existência como um antípoda ao direito de propriedade, alicerce fundante da ordem burguesa. Suas primeiras manifestações em sua defesa remetem à "Moi, la révolution" - interessante obra em que ao assumir vezes de alter ego feminino, a Revolução, narra as venturas e desventuras do processo inaugurado na França em 1789 -, marco decisivo na inflexão de sua postura enquanto intelectual público (LÖWY, 2020). Ao remeter às proposições de Robespierre pela afirmação de um direito natural à existência, contraposto ao caráter absoluto que o direito de propriedade vinha assumindo nos marcos legais e constitucionais revolucionários, prefigura o jurista radical como proponente moderno da bandeira política - tão em voga e tão combatida na atual conjuntura assolada pela COVID-19 - de que a vida deve prevalecer ante as bases econômicas capitalistas. 
Esta chave servirá a Bensaïd para debater outras realidades, como se nota por suas considerações acerca dos processos de cercamentos e despossessão que marcam a acumulação originária de capitais desde a realidade europeia (BENSAÏD, 2007) - muitas destas discussões voltadas a debater a atualidade de primevo ensaio marxiano acerca das leis referentes ao furto de madeira (MARX, 2017) - e as contemporâneas ondas de apropriação dos bens de vida, seja pela proeminência que assumem as patentes, seja pela cadência irrefreável do capitalismo em mercantilizar tudo que não esteja ainda posto em comércio (BENSAÏD, 2003; 2007; 2008).

Deste conjunto de referências e objetos de atenção Bensaïd conformará importante contributo à reflexão crítica do direito, sobretudo ao pensar que a tradição dos pobres e o exercício dos seus modos tradicionais de vida não mercadorizados constituiriam as bases deste Direito à Existência, precedendo este - não só cronologicamente, quanto moralmente - à afirmação do direito de propriedade capitalista. A questão cronológica, na discordância dos tempos tão própria de seu pensamento (BENSAÏD, 1995), aparece subvertida também, haja vista que ante a dominância da propriedade privada das nossas condições de existência, o apelo ao Direito à Existência e desmercantilização do que já foi mercantilizado se colocam como horizontes importantes na luta do conjunto dos atores sociais explorados e oprimidos na sociedade capitalista.

Estas provocações trazidas por Daniel Bensaïd nos servem fundamentalmente a pensar o Direito à Existência dentro de dimensões propriamente econômicas, sociais e biológicas, haja vista operar enquanto garante dos meios de sustento, reprodução da vida e da sociabilidade próprias das parcelas da humanidade que, nos mais diversos momentos sócio-históricos, foram despossuídas de seus meios tradicionais de vida, ou como meio estruturante de uma nova forma de organização das existências, avessa ao domínio mercantil, como pugna a sociedade do capital.

Partindo desta base é que pretendemos derivar algumas reflexões, não desenvolvidas por Bensaïd, e que com amparo na tradição marxista podem servir à complexificação e adensamento do trato do Direito à Existência.

A primeira destas derivações decorre do fato de que o Direito à Existência não poderia se resumir a uma construção com vistas a objetivos 
materiais apenas e tão somente. Esta leitura, comodista desde um referencial político, facilmente capturável pela institucionalidade servil ao capital e sem horizonte estratégico, soaria condescendente às perspectivas exclusivas de reprodução material das trabalhadoras e trabalhadores, tão úteis à perenização dos ciclos capitalistas. Deve sim o Direito à Existência ser permeado por uma essência tática, lastreado na afirmação de condições elementares de vida e sociabilidade para o impulsionar da ação revolucionária do proletariado (SEFERIAN, 2017).

Feito esse anúncio, convém enfrentar importante e controversa questão, qual seja, a possibilidade de defesa da mediação do direito a partir de um referencial revolucionário marxista.

Dentre as diversas tradições que reivindicam o legado marxista, existe uma particular que bebendo da obra marxiana - seja em suas referências textuais, seja em seus alicerces metodológicos -vinculará de forma indissociável o direito à mercadoria, associando o aperfeiçoamento da forma-jurídica, que chega ao seu ápice no capitalismo industrial, ao desenho mais bem-acabado da forma-mercadoria. E é na apreensão da Teoria Geral do Direito e o Marxismo, de Evgeni Pachukanis (2017), que se encontra a ainda insuperável contribuição à leitura do direito nesse sentido. Firmamo-nos nela para nossa leitura da juridicidade. Mas reconhecemos que ainda que não superada, comporta essa abordagem canônica apreensão crítica e matizada, o que vem ao arrepio das suas leituras hegemônicas, que a absolutizam em sua conformação originária (por todos, MASCARO, 2013).

Pachukanis, por certo, não se empenhou em debater a juridicidade na particular conformação dos direitos sociais, tendo inclusive anunciado merecer sua empreita desdobramento nos mais diversos ramos jurídicos (PACHUKANIS, 2017, p. 55-56), haja vista não tê-lo feito. Daí sua teoria merecer flexão derivativa às particularidades constitutivas do Direito do Trabalho, da Previdência Social, da Assistência, Ambiental e outros Direitos Sociais. Ademais, parece ressoar de sua obra - e também de suas traduções para o português - uma confusão entre direito em geral e a juridicidade em particular - esta última tipicamente capitalista (SEFERIAN, 2017)-, o que geraria incongruências na busca da consecução de horizontes políticos e sua 
mediação pelos direitos. Desse modo, ainda que saibamos a autonomia relativa existente entre os campos do direito e da política, bem como os limites estruturais do primeiro e as potências da segunda, reivindicar direitos não importaria, aos nossos olhos, em reivindicar a submissão à juridicidade. Poderia, muito pelo contrário, importar na projeção da política sobre a formajurídica, com vistas à sua ruptura ou, quando não, na sua operacionalização consciente como base de resistência para acumulação de forças das classes trabalhadoras para condução de movimentos de caráter radicalmente transformadores.

Ademais, reconhecer as contradições imanentes ao direito como um todo - ou seja, em suas expressões históricas pré-capitalistas - e à juridicidade em particular - em outras palavras, ao direito moderno, próprio da sociedade capitalista e industrial - nos leva à conclusão de que não soa inapropriada a defesa, dentro de seus limites, da mediação do direito como bandeira transitória. Nossa crença não reside, pois, em uma defesa incondicional da mediação do direito, sobretudo em sua conformação mais aperfeiçoada às funcionalidades capitalistas - a da forma-jurídica (PACHUKANIS, 2017) -, mas sim numa possibilidade de projeção tática na salvaguarda de direitos.

Trata-se, ademais, de uma questão de concepção: não nos caberia desde uma perspectiva acadêmica apontar qual o mais adequado elemento de mediação das lutas conduzidas pelos movimentos sociais, sobretudo em um momento de retração das forças de exploradas e oprimidas, em que a ofensiva do capital se coloca em escalada global na forma de uma contrarrevolução de matiz neoliberal (ANTUNES, 2019). Daí que não podemos deixar de lado que, historicamente, dos versos d'A Internacional às pautas de diversos movimentos de caráter anticapitalista e revolucionário, a defesa de direitos é entoada.

É inclusive do reconhecimento da potência revolucionária inscrita na própria constituição das classes trabalhadoras e na crença na sabedoria autodeterminada dos movimentos populares que não podemos nos furtar ao reconhecimento da existência de pautas transitórias jurídicas que nos levem à consecução da tarefa maior revolucionária.

Daí também não poder se resumir o Direito à Existência a um repertório exclusivo de direitos positivados, ou mesmo em lutas sociais que se esgotam na 
disputa pela consagração destes. Uma perspectiva que se limita a tal fim não pode se desenlaçar das teias da juridicidade, que a todo custo busca "capturar" as demandas do movimento de oprimidos e oprimidas (EDELMAN, 2016), interditando seu perfilamento a um horizonte estratégico revolucionário.

O exemplo colocado por Edelman (2016), aliás, é emblemático nesse sentido: abordando a matéria da greve, aponta que porquanto utilizada como instrumento político pelas classes trabalhadoras para tensionar a lógica de exploração das classes proprietárias, surtia essa efeitos políticos mais benfazejos aos interesses maiores daquelas e daqueles que vivem da venda da sua força de trabalho, que podemos aqui sintetizar como seus meios maiores de existência e garantia de vida. Ocorre que no transcorrer histórico, a agência dos movimentos grevistas acaba por ser contemplada pela lógica de normalidade burguesa, que o "captura" enquanto um direito que toda trabalhadora ou trabalhador passa a gozar. Na forma de direito, porém, a greve passa a ser parametrizada, condicionada, e todo e qualquer sinal de "fuga" dos referenciais estabelecidos legalmente para seu exercício passam a ser considerados abusivos, atentatórios ao direito burguês. Em suma, a greve, enquanto manifesta como exercício do “direito de greve", se neutraliza enquanto movimento e meio de luta social e classista, e passa a se realizar apenas dentro das balizas inofensivas ao capital pelas quais é enquadrada. Reflexão assemelhada, bem vale dizer, é conduzida por Márcio Túlio Viana (2000), no prefácio elaborado à obra "Direito do Trabalho como instrumento de Justiça Social”, de Jorge Luiz Souto Maior (2000).

Trata-se, pois, na compreensão que dimana dos debates marxianos publicados na Gazeta Renana, da colisão que suplanta o debate do direito mas que, dada a sua historicidade, também se constitui enquanto tal, para além de denotar sua relevância política e já econômica - e se conforma na afronta de duas tradições: a dos pobres e a dos proprietários (MARX, 2017).

A remissão ao quase bicentenário texto de Marx não é ociosa, sobretudo quando temos em conta que setores cada vez mais amplos da população são, à luz - ou sombras - do interesse nu e cru do capital considerados descartáveis, sendo vítimas de suas políticas de morte (MBEMBE,2018). Ocorre que nem sempre os remédios buscados pelas classes proprietárias age a contento em 
defesa de seus interesses. Em muitas circunstâncias, o que se busca em verdade é apagar um incêndio com gasolina.

É exemplo disso a perspectiva de redução do preço da força de trabalho para patamares abaixo de seu valor. Esse quadro de coisas, que em nossa realidade dependente e periférica manifesta o que Ruy Mauro Marini (2000, p.160) caracteriza como de superexploração - ou seja, circunstância em que se dá "maior exploração da força física do trabalhador, em contraposição à exploração resultante do aumento de sua produtividade e tende normalmente a expressar-se no fato de que a força de trabalho se remunere por baixo de seu valor real" -, proporcionam de um lado a efetivação dos processos de acumulação flexível (HARVEY, 2014, p. 177-184), que servem de fôlego ao moto expansivo capitalista em crise, mas de outro e contraditoriamente atenta contra as próprias perspectivas de reprodução da vida social de trabalhadoras e trabalhadores, o que coloca em risco a própria perpetuação da relação social do capital.

Reivindicar, pois, a salvaguarda desta primeira dimensão do Direito à Existência - ou a possibilidade de condições de sobrevivência para trabalhadoras e trabalhadores, em receber em todo o globo terrestre, mas mormente nas nações periféricas e dependentes, dentre as quais se encontra o Brasil, um salário balizado dentro das referências típicas da equivalência lastreadas na teoria do valor marxiana - mostra-se atentatório aos sustentáculos da acumulação capitalista na contemporaneidade, já que esta não consegue subsistir sem avançar contra os meios mais elementares de vida das classes exploradas.

Não ousamos dizer que a reivindicação pela aplicação do imperativo da equivalência na compra da força de trabalho seja, per si, antissistêmico, mas por certo resulta em afronta aos desenhos colocados na contemporaneidade para recomposição das dinâmicas da sociedade da mercadoria, mormente no que se refere aos registros de normalidade funcionais ao regime de acumulação de capitais hoje em vigor.

Este diagnóstico vale também a outras experiências históricas relevantes, ligadas à existência e ao meio ambiente, que expomos a título de exemplo: de um lado, os movimentos sociais que buscavam a regulação de 
preços e se colocavam contra a carestia e o aumento dos custos de vida, como foi o histórico Movimento Contra a Carestia-MCC (NUNES, 1987). De outro, o conjunto de movimentos sociais que hoje intervém contra a sanha lucrativa das grandes mineradoras do país, como o Movimento de Atingidos por Barragens$\mathrm{MAB}$, que não se coloca contra a mineração em absoluto, mas busca apenas a inflexão na lógica pautada pelo lucro e afrontosa à soberania nacional impressa pela atividade extrativa no país (BRASIL DE FATO, 2019).

É de se ter em conta que o primeiro movimento se colocou em luta pela redução de preços de bens materiais de primeira necessidade, sobretudo no período de transição à democracia formal brasileira, e não levantou propriamente a bandeira da gratuidade dos produtos indispensáveis à reprodução da existência ou o controle popular da produção destes itens vitais. Já o segundo, que mesmo se mostrando um entrave às grandes mineradoras multinacionais, ainda se vê movido por uma leitura dos meios de produção marcada por um Progresso maiúsculo, sendo pouco crítica à dependência das práticas extrativas em geral. Nada disso eclipsa o papel relevantíssimo que cumprem na contenção às ganas expansivas capitalistas, mas de outro lado revelam os limites por eles postos na consagração de tensões sistêmicas que possam ensejar rupturas com as práticas predatórias das condições de vida e de existência da natureza não-humana hoje dominantes.

Assim, se não recaem na crença ancorada em referências abstratas e vazias de sentido - quando não permeadas de registros burgueses, como o da busca de uma existência "digna”, sustentável e compatível com a ordem do capital -, não sinalizam ruptura efetiva com a ordem social posta. O que pretendemos, ao revés, é sim buscar a construção de um Direito à Existência que se coloque como referência transgressora e negativa da própria ordem. Que, em sua potencialidade tática, abra fissuras ao expor de contradições nos pilares que dão sustentação à ordem tal qual ela se estabelece.

Deste modo, o Direito à Existência, por mais que vise em uma primeira expressão mais intuitiva e imediata - como a que preocupa Bensaïd - a salvaguarda das condições de existência material das pessoas exploradas e oprimidas, não pode se limitar à sua constância serena no cerne de uma ordem social que coloca como missão fazer ruir estes mesmos meios de vida. Deve 
galgar um horizonte outro, distante destes marcos estruturais atentatórios à existência em si.

É ai que irrompe a segunda faceta do Direito de Existência, ao lado de um “direito à vida” (BENSAÏD, 2017), ou um "direito dos pobres” a que Marx (2017) faz menção. Dialeticamente imbricado a esta dimensão, há a afirmação da existência política das classes trabalhadoras e das oprimidas e oprimidos em suas lutas auto-organizadas.

Esta dimensão política acentuada decorre de ser tão grave quanto a impossibilidade de sobrevivência material das trabalhadoras e dos trabalhadores, das oprimidas e oprimidos, o cerceamento de sua ação política com vistas à consecução seus anseios históricos de libertação.

Deste modo, nossa proposta de existência - ou da defesa de um Direito à Existência - se coloca, assim, também na própria constituição das classes sociais e dos setores oprimidos da sociedade, indo além de seu simples aspecto corpóreo e econômico.

Bebemos da compreensão lançada pelo historiador e militante inglês Edward Palmer Thompson em seu A formação da classe operária inglesa, obra em que traz como uma de suas grandes contribuições ao campo do conhecimento histórico a compreensão de que a constituição das classes sociais não se dá pela simples relação existente entre um agrupamento de sujeitos, em cada realidade sócio-histórica, com os meios e relações de produção. Das múltiplas determinações que constituem as classes sociais - e também podemos dizer os grupos oprimidos das sociedades - está a sua própria dinâmica de luta enquanto constituinte. Daí compreender o autor britânico que as classes se fazem em processo, com esteio em elementos culturais e por meio da luta de classes (THOMPSON, 1987). Luta esta que, como Marx e Engels já apontaram, ora se mostra mais velada, ora mais aparente, "ora franca, ora disfarçada" (MARX; ENGELS, 2010, p 40), mas que perpassa a totalidade das relações existentes entre sujeitos de classes distintas, antagônicas ou não, nas sociedades históricas.

Considerando assim que as classes sociais se constituem em luta, é pela luta, pelo colocar-se em movimento que se vertebra sua existência. E para tanto, há de se reclamar condições materiais e políticas, propriamente, para que 
se travem explicitamente tais enfrentamentos, sobretudo numa perspectiva de ofensiva e afirmação de seus reais interesses sociais, econômicos e históricos. Deste modo, se evidencia também enquanto direito para que trabalhadoras e trabalhadores constituam-se enquanto classe, e que setores oprimidos se autoorganizem, colocando-se em movimento e travando explicitamente embates classistas.

\section{Unidade dialética do Direito à Existência desde uma abordagem estrutural}

Expostas as duas facetas do Direito de Existência tal qual o concebemos, por certo poderiam nos confrontar com leituras que as considerem como direitos não só de funcionalidades como de naturezas distintas. Para nos utilizarmos de um jargão costumeiro, constituiriam-se as premissas de sustentação material conferidas a exploradas e oprimidas um conjunto de Direitos Sociais, e as perspectivas de auto-organização e atuação em prol de seus interesses como direitos políticos (por todos, COMPARATO, 2017). Ocorre que entendemos guardar uma convergência inextricável entre estas duas dimensões, que deve ser lida de forma unitária, enquanto um Direito à Existência.

A primeira premissa que tomamos para tanto é o fato de não se poder entender o conjunto de articulações políticas dissociadas das conquistas sociais, e vice-versa, como se passíveis de compreensão em dimensões ou gerações, como convencionou a teoria clássica dos Direitos Humanos classificar (COMPARATO, 2017), ou então como etapas distintas em um processo de aprofundamento revolucionário, como a vulgata estalinista abordou a leitura da revolução socialista na primeira metade do séc. XX. Tomando a forma desigual e combinada como o modo de produção capitalista se desenvolve, e o modo como a revolução deve ser conduzida de modo permanente (TROTSKY, 2007; 2011; LÖWY, 2015), é que nos calcamos na indispensabilidade de que pautas políticas e sociais se unam, compreendendo que mutuamente se determinam, e que conjuntamente devem ser afirmadas.

Talvez desde uma tomada negativa esta leitura que conecta dimensões sociais e políticas passe a se verificar de modo mais nítido. E aqui o modo como 
no último período o conjunto de contrarreformas destinadas à destruição das condições de vida de exploradas e oprimidas se operacionalizou sinaliza sintomaticamente este fato. Ainda que de forma contraditória e atentatória à própria lógica do capital, a ofensiva burguesa contrária a existência das classes trabalhadoras e dos setores oprimidos no Brasil proporcionou a ampliação de tempos de trabalho, precariedade de vínculos, minoração da renda pelo salário - sobretudo com a Lei n. 13.467/2017 -, a intensificação da fragmentação social pela terceirização ampla e irrestrita - advinda com a Lei n. 13.429/2017 -, a restrição a benefícios previdenciários - advindos da contrarreforma da Previdência instituída pela Emenda Constitucional n. 103/2019 -, a restrição de gastos públicos com serviços essenciais à população - operacionalizada pela Emenda Constitucional n. 95/2016 -, para além outras tantas medidas que minaram material e politicamente as existências de exploradas e oprimidas, em um mesmo tacão, como parte de um mesmo projeto estratégico de perenização de interesses capitalistas.

É bem evidente, deste conjunto de inflexões jurídicas, como as formas de pauperização de exploradas e oprimidas se verifica. Minoração de renda, interdição a gozo de benefícios sociais e projeção à aquisição no mercado de serviços indispensáveis outrora conferidos pelo Estado - como saúde e educação - são consequências evidentes destas medidas. Subterrânea, porém, e bastante mais mediada é a fragilização política delas advinda.

E aqui podemos nos amparar em alguns exemplos ilustrativos para tanto:

a) olhando a contrarreforma trabalhista instituída pela Lei $n$. 13.467/2017, percebemos como a instituição de formas precárias de contratação (como os vínculos intermitentes) e a permissividade exploratória sem peias negativas (como a universalização da jornada 12x36) reclamou do conjunto de pessoas exploradas e oprimidas que não só se sujeitassem a condições mais incertas de obtenção de renda, como também a se sujeitar a plurais postos de trabalho para poder obter renda suficiente para sustento próprio e de familiares. Tais fatores impossibilitam materialmente e existencialmente a participação em espaços políticos auto-organizados (como sindicatos, associações de bairro e profissionais etc.), para além de levarem, estruturalmente, esse conjunto de 
pessoas a nem mesmo conseguir pensar criticamente as suas condições de existência e o que as leva a assim viver;

b) A mesma Lei n. 13.467/2017 trouxe toda uma série de impactos às condições de sobrevivência das entidades sindicais no país, sobretudo por extinguir a contribuição sindical, principal forma de arrecadação dos sindicatos brasileiros. Muito embora extremamente limitada seja a atuação sindical no país, sobretudo ante sua estrutura burocratizada e de umbilical ligação histórica com o Estado, ainda assim foi espaço privilegiado para atuação política de trabalhadores e trabalhadoras na sua construção para-si ( LUKÁCS, 2003). Ocorre que com tais alterações, as potencialidades combativas - já outrora reduzidas - e negociais - historicamente privilegiadas - se veem minguar ainda mais, como apontam estudos empíricos fundados em dados do IBGE e DIEESE (BATISTA, SEFERIAN, no prelo);

c) Já a Lei n. 13.429/2017, para além de proporcionar o aprofundamento das condições precárias de trabalho a uma ainda maior fração das classes trabalhadoras, com minoração de renda, aumento do grau de acidentalidade e redução do tempo de permanência nos postos de trabalho, acabou resultando uma fratura - também experimentada simbolicamente, na vivência cotidiana dos espaços de trabalho - na identidade dos trabalhadores e trabalhadoras, intensificado pela já mencionada estrutura sindical de Estado brasileira, tornando ainda mais difíceis as perspectivas de integração política no enfrentamento de interesses comuns entre pessoas terceirizadas e nãoterceirizadas (BATISTA, SEFERIAN, 2018);

d) No momento em que concluímos o presente texto, o país - assim como todo o globo - se vê assolado pela pandemia da COVID-19. Este processo mostra o quanto que as carências de investimento na saúde pública e em pesquisa, bem como a permissividade para com práticas precarizantes de trabalho, podem trazer efeitos extremamente perversos às classes trabalhadoras em suas condições dúplices de existência. Tendo em conta que de um lado se vivencia estranha e inédita realidade de confinamentos residenciais, com interrupção de serviços diversos e atividades produtivas muitas, tudo visando a preservação individual da saúde tendo-se em conta sobretudo a incapacidade do sistema de saúde em atender tão grande demanda de internações - o que 
impede estruturalmente os contatos e trocas sociais costumeiras, condição indispensável às articulações e saldos políticos -, de outro se verifica a responsabilização de trabalhadores e trabalhadoras pelos ônus desta crise, já que são onerados tanto os precários - que sem trabalhar, não têm como receber renda alguma para seu sustento material - quanto estáveis - que se veem sujeitos a regras que facilitam dispensas, precarizam seus vínculos, possibilitam os acordos individuais indecorosos entre quem trabalha e quem explora, como as advindas das Medidas Provisórias 927 e 928, de 2020 - para que deem azo às suas condições de existência; entre outros.

Inegável, pois, que a precariedade das relações de trabalho e dos meios de obtenção de renda é, pois, a precariedade de condições para a autoorganização e autodeterminação classistas. A exclusão do gozo deste Direito à Existência - em suas dimensões social e política - é a chave para a exceção da vivência política, da constituição dos sujeitos históricos em-si e para-si (LUKÁCS, 2003). Até porque não nos parece apropriado pensar que a apologia da barbárie - uma lógica do "quanto pior, melhor" - é condição para a afirmação política consciente e transformadora das classes trabalhadoras e dos setores oprimidos da sociedade. Nos alinhamos de forma diametralmente oposta a essa impressão, crendo que a melhoria material das condições de vida - salvaguardada, por exemplo, pelo pleno emprego sem baixos salários possibilita o fazer político das classes trabalhadoras (MANDEL, 1982, p. 27).

Logo, a precariedade das condições de vida resulta na precariedade da ação política.

\section{Meio ambiente e Direito à Existência}

Desta dúplice percepção do Direito de Existência despontam a preocupação da lida dos movimentos sociais em sua consagração, fato que em alguma medida já foi tangenciado nos itens precedentes.

Questão fundamental que se coloca aqui remente à necessidade de reconhecimento de uma pluralidade ampla de movimentações das classes trabalhadoras e setores oprimidos como constitutivas do que concebemos movimentos sociais. Esse fato faz com que não apenas abarquemos processos de 
organização e luta por pautas particulares e específicas de existência - como terra, moradia, minoração de preços, saneamento básico, saúde pública etc -, como também articulações políticas mais amplas, como de caráter partidário, e sindicais (AGUITON, BENSAÏD, 1997). Tendo em conta a perspectiva de classe que assumimos - que nos levar a ver o Direito à Existência também desde o lado das exploradas e oprimidas -, não parece ocioso mencionar que ao tratarmos do assunto não estaremos aqui objetivando movimentos - também sociais - sem caráter popular, como é o caso do conjunto de articulações que se colocaram massivamente em ação às vésperas e após o golpe de Estado ocorrido em 2016.

Dito isso, parece-nos fundamental pensar como estruturalmente as articulações das lutas destes movimentos sociais, de conjunto, remete necessariamente à luta enredada por pautas ambientais.

Retomando aspectos conjunturais, é de se ter em conta que o conturbado ambiente de ofensiva contrarrevolucionária da burguesia - de matiz preventivo e internacional -, que coloca nas contrarreformas sociais e políticas sua principal toada e que desde o irromper da crise econômica experimentada na primeira metade da década de 1970 se agudiza, que os elementos de ordem ambiental são também marcadamente vistos. Ainda que estas marcas sejam bastante mais evidentes nos países centrais da ordem, em que um Estado Social foi experimentado, estes traços também se emulam de forma desigual e combinada desde as perspectivas dependentes e periféricas da ordem.

Este sismo chega ao Brasil de forma modulada e tardia, quando comparada aos países centrais da ordem. Isso por decorrência de se experimentar, desde o fim dos anos 1970, um conjunto de mobilizações sociais que servirão de base à redemocratização formal do país após uma década de lutas - originalmente verificado no bojo do movimento operário, mas que futuramente se irradia no âmbito do movimento de mulheres, negras e negros, pela saúde, contra a carestia etc -, galgando saldos em prol da vida e do Direito à Existência e atrasando em quase vinte anos o reordenamento econômicopolítico no país a partir de marcos neoliberais.

A inflexão dessa realidade começa a se experimentar apenas após o novo pacto político que enseja a Constituição de 1988, que sucede, no âmbito 
global, ao erigir do consenso burguês do fim da história (FUKUYAMA, 1992), que impacta sobremaneira na efetivação de seus primados sociais e econômicos.

Ao mesmo passo este ideário passava a se avolumar, tanto no campo jurídico quanto nas perspectivas políticas - donde o exemplo da repressão da greve dos petroleiros, em 1995, e o massacre dos sem-terra em Eldorado dos Carajás, em 1996, talvez sejam das mais evidentes expressões - o conjunto dos movimentos sociais era atacado duramente e interditado de ter suas condições de existência consagradas.

No campo institucional, percebeu-se nos governos que sequenciaram a redemocratização formal toda uma série de benesses. Aos setores industriais e comerciais, os permissivos para o trabalho por tempo determinado(Lei $\mathrm{n}$. 9.601/98), a denúncia da Convenção 158, da OIT (Decreto n. 2.100/1996), a legalização de cooperativas (Lei n.8.949/1994), dentre outros, cumpriram um papel fundamental para proporcionar a ampliação das margens de lucro e lesar as condições de existência daqueles e daquelas que trabalham. Já o agronegócio, principal responsável em nosso quadrante histórico pela manutenção da desigual distribuição de terras em nosso país e por impulsionar o movimento de trabalhadoras e trabalhadores do campo pelo acesso a meios de vida e trabalho, o governo Fernando Henrique Cardoso:

Durante o segundo governo de Fernando Henrique Cardoso (1999- 2002), os investimentos no agronegócio são reforçados através das seguintes iniciativas: a) um programa prioritário de investimento em infraestrutura territorial, visando a criação de economias externas que incorporassem novos territórios, meios de transporte e corredores comerciais ao agronegócio; b) um explícito direcionamento do sistema público de pesquisa agropecuária (Empresa Brasileira de Pesquisa Agropecuária Embrapa), operando em sincronia com empresas multinacionais do agronegócio; c) uma regulação frouxa do mercado de terras, de modo a deixar fora do controle público as terras devolutas, mais aquelas que declaram não cumprir a função social, além de boa parte das autodeclaradas produtivas; d) a mudança da política cambial torna a economia do agronegócio competitiva junto ao comércio internacional e funcional a estratégia de ajustamento macroeconômico; e) a provisão de crédito rural nos Planos Safra é retomada em vigor no período de 2003-10 (BARROS, 2018, p.180-181)

Esta tônica manteve-se nos anos de governo social-liberal do Partido dos Trabalhadores (CASTELO BRANCO, 2008), que não proporcionaram 
inflexões abruptas nas políticas em prol do capital conduzidas em momentos anteriores e proporcionaram o aprofundamento - ainda que muito mais tímido - nas perspectivas de existência e auto-organização. Mesmo em um cenário que se percebeu um acréscimo de renda do conjunto dos trabalhadores e trabalhadoras, tais marcos de existência se viram corroídos pelo endividamento, como bem observam Matheus Itiro de Castro Tao e Dayani Cris de Aquino, ao estudarem a renda de núcleos familiares (TAO, AQUINO, 2019).

Mas não só: também o imobilismo a que uma série de movimentos populares se viram sujeitos por sua institucionalização e burocratização nos 13 anos de governo do Partido dos Trabalhadores é algo notável, proporcionando fenômenos profundamente contraditórios, como o refreamento das políticas de reforma agrária (COSME, 2016) e o direcionamento de trabalhadores e trabalhadoras na gestão de fundos públicos de investimento financeiro (OLIVEIRA, 2010). Mais grave, porém, foi o recrudescimento das medidas penais, muitas delas decorrentes da submissão às agências imperialistas da FIFA e do COI, que dentro de uma perspectiva de exceção não só proporcionaram a criminalização de lutadores e lutadoras sociais pelos instrumentos jurídicos já existentes no país, como também instituíram novos remédios ainda mais perversos, a exemplo da famigerada Lei Antiterrorismo (Lei n. 13.260/2016), que já afeta diretamente a luta social no país, a exemplo dos incidentes de criminalização do Movimento dos Trabalhadores Sem-Terra de Goiás (BENITEZ MARTINS, 2018).

Todavia, a velocidade que as contrarreformas e as perspectivas de criminalização e neutralização dos movimentos sociais no país se catalisou após o golpe de Estado de 2016, e as alterações na CLT e no regime da previdência gestadas nos governos anteriores foram implementados rapidamente, e sendo insuficientes o conjunto de lutas conduzidas por movimentos sindicais, estudantis e de trabalhadores e trabalhadoras do campo que se colocaram em resistência, sobretudo por saírem de um ponto de repouso total. A aprovação da Emenda Constitucional n. 95/2016 e a contrarreforma do Ensino Médio foram os primeiros passos, que seguiram se aprofundando com a contrarreforma trabalhista e, depois da eleição de Jair Bolsonaro, previdenciária. 
$\mathrm{Na}$ conjuntura que se experimenta desde o início de 2019, ainda mais agravadas são as condições de auto-organização, mobilização social e sindical, sendo diversos os repertórios de ataque: de um lado, uma propagação de ameaças e destilação de ódio deliberadas pelo próprio Presidente da República, que mesmo antes da posse mencionou que varreria do país os "bandidos vermelhos", aludindo diretamente ao Movimento dos Trabalhadores Sem-Terra (MST) e ao Movimento dos Trabalhadores Sem-Teto (MTST) (CARTA CAPITAL, 2018). De outro, medidas como a Medida Provisória n.873/2019, que intentou estrangular os orçamentos dos sindicatos de empregados e empregadas. Elementos todos que, junto às medidas de exceção que já passam a se experimentar desde o dia 1 do governo, e que se agudizam no cenário da crise sanitária proporcionada pela COVID-19, que levam não só à evidenciação de toda corrosão dos serviços públicos no país, bem como escancaram como tais políticas colocam a primazia das ações públicas ao primado do lucro, tudo em detrimento da vida.

Mas não se resumem apenas a esta dimensão da existência dos trabalhadores e trabalhadoras as políticas conduzidas no país no curso dos últimos trinta anos. Imbricada às duas dimensões do Direito à Existência, é fundamental olharmos para o tema ambiental a fim de perceber, de um lado, como ele se articula às perspectivas de existência material e política das exploradas e oprimidas, e de outro lado, o quanto se coloca como imprescindível a adesão do conjunto de movimentos sociais, tal qual é a percepção da luta de classes, de se empenhar na adesão a lutas ambientais.

Remontando historicamente um panorama tal qual o acima lançado, é de se perceber que também no que se refere às políticas ambientais os ataques no país foram profundos, e acompanharam o mesmo compasso de intensidade e forma que as contrarreformas violentas voltadas a conquistas sociais e políticas cristalizadas institucionalmente no país. Daí pretendermos demonstrar como existe uma sintonia nestas ofensivas, que se articulam na busca de um interesse comum, qual seja, o fomento das políticas do lucro do capital.

Da mesma sorte que outras conquistas políticas e sociais, a lida ambiental inicia-se a ruir com o arrefecimento dos movimentos sociais que se colocaram na ofensiva nos anos 1980. Também contaminadas pelas 
perspectivas do fim da história, os movimentos ambientalistas no país assumiram um papel fortemente condescendente com uma tônica adesista ao regime de acumulação de capitais.

Este clamor se viu animado pela realização da Conferência das Nações Unidas sobre o Meio Ambiente e o Desenvolvimento dada no Rio de Janeiro em 1992 (também conhecida por Eco-92 ou Rio-92), que enraizou perspectivas ambientalistas associadas ao aprimoramento do modo de produção capitalista, proporcionando seu desenvolvimento sustentável, sem cogitar qualquer ruptura com esta ordem social.

Acompanhando as ofensivas contra os lutadores sociais do campo, nos governos Fernando Henrique Cardoso a privatização do modo de gestão das políticas ambientais (CÂMARA, 2016), no mesmo compasso da privatização de empresas públicas diretamente ligadas ao processo extrativo, sinaliza que seus desígnios seguiriam sendo pautados pela lógica do lucro, agora em sua feição financeirizada.

Tal fato traz impactos soberbos ao direcionamento de políticas pelos movimentos sociais, sobretudo diante dos novos desenhos econômicos que passam a constituir os seus inimigos a serem derrotados, mas também diante da dimensão de anonimato e blindagem formal instituída pelas empresas de capital aberto, que passam a ser as principais interessadas na ofensiva contra a existência direta dos trabalhadores e trabalhadoras pelo desmonte trabalhista, pela disputa dos fundos públicos de investimento e também pela captura dos bens naturais indispensáveis ao bem-viver do conjunto de exploradas e oprimidas.

A cadência segue a mesma também nos governos do Partido dos Trabalhadores, mas tal qual os ataques a direitos políticos e sociais, também neste importante condicionante à existência humana aparecem as ofensivas bastante maquiadas, ainda que não menos ecocidas. Dando sustentação e aprofundamento de medidas de gestão neoliberais, é de se perceber toada ideológica do projeto de desenvolvimento social-liberal dos governos do Partido dos Trabalhadores (2003-2016), produtivista e avesso às lutas ecológicas. A construção das usinas de Jirau e Belo Monte, a implementação do novo Código Florestal (Lei n. 12.651/2012) e o realinhamento econômico em marcos neo- 
extrativistas são características desta ofensiva, que guarda nas políticas de mineração um dos seus mais evidentes exemplos (MILANEZ, SANTOS, 2013).

Imbricada com a questão ambiental encontram-se também os efeitos da contrarreforma rural, que não só se conecta aos interesses voltados ao agronegócio - em que o já mencionado Código Florestal é expressão evidente -, mas também se manifesta na já mencionada captura dos movimentos de trabalhadoras e trabalhadores do campo pela institucionalidade, a minoração de famílias assentadas, as propostas que aumentam a permissividade predatória do trabalho camponês - como se expressa no PL n. 6442/2016, que intenta proporcionar o aumento de percentual do salário pago in natura -, as disputas semântico-jurídicas colocadas no trato do trabalho escravo, que tanto aflige o trabalhador e a trabalhadora rurais (SEFERIAN, 2018), e a financeirização do fomento à agricultura familiar, que, ainda que visto por alguns setores que se vindicam de esquerda como uma política classista, por certo não pode assim se caracterizar.

O mesmo agronegócio é o vetor fundamental de outra fronteira da ofensiva burguesa, que se volta contra às populações tradicionais e indígenas, que em função de seus arranjos de trabalho, sociabilidade e lida com a terra e o meio ambiente acabam por representar a negação das perspectivas de afirmação capitalistas. Assumem, pois, a restrição da demarcação de territórios indígenas e ampliação dos entraves burocráticos para reconhecimento das comunidades tradicionais um lugar de destaque no rol de medidas do capital no último período (GREENPEACE, 2020).

Tais ataques às populações tradicionais - que passam pela difamação, desapropriação e crimes de sangue - revelam uma das faces emblemáticas do capitalismo, acentuado pela sua conformação neoliberal: frente às ganas do lucro, amplos setores da população tornam-se dispensáveis, descartáveis (MBEMBE, 2018). Podem - e devem, em alguns casos - ser exterminados, seja pela resistência que impõem, seja pelo cálculo frio para composição do exército industrial de reserva e consumo. São parte do mesmo movimento, em fronts distintos, o assassinato em massa de indígenas e camponeses que resistem ao latifúndio e sua lógica oligárquico-mafiosa, o genocídio - acompanhado pelo encarceramento em massa - da população jovem e negra das periferias 
brasileiras, as manifestações de ódio que se voltam à população LGBT, sobremaneira manifesta nos crimes transfóbicos direcionados a travestis e transexuais, e a condescendência invisibilizadora e naturalizante para com o machismo e o feminicídio.

Não obstante nossa exposição nesse item tenha se atido a exemplos da realidade brasileira, todas as frentes aqui anunciadas também foram profundamente atacadas mundo afora. São exemplos, na conjuntura global, a escalada das políticas de austeridade vivenciadas na Europa após 2008, a falência do Acordo de Paris, com a debandada estadunidense - que soa como ricochete ao imenso retrocesso cristalizado pela eleição de Trump, que em terras brasileiras encontra sua paródia farsesca, para nos utilizarmos a chave do 18 de Brumário de Luis Bonaparte (MARX, 2011) -, o compactuar dos governos burgueses com toda uma gama de assassinatos de lutadoras e lutadores das causas ambientais - ranking que o Brasil encabeça (THE GUARDIAN, 2017) - , a constituição de bolsões de descaso ambiental mundo afora, que assola as populações mais pobres, seja dos países dependentes e periféricos, seja dos centrais da ordem (KEUCHEYAN, 2018;TANURO, 2012), os atentados que se voltam às populações camponesas e tradicionais na América Latina, África e Ásia, a guerra imperialista na Síria, entre outras medidas. São todas essas situações sintomas da face internacional desse movimento amplo, que se desenvolve de forma desigual e combinada na ordem internacional, com particularidades em cada estado-nação.

Mundialmente, esta caracterização quanto ao aprofundamento crise civilizacional - anunciada nas primeiras linhas deste escrito - desde a perspectiva ecológica se coloca ainda mais convulsionada ante os efeitos sanitários que passam a expressar nos meses que antecedem à conclusão deste texto, com redação final de meados de 2020. Tal crise sanitária por certo guarda uma imbricada relação com elementos ecológicos, tanto no que se refere à origem da contaminação humana com a COVID-19 - que independentemente da hipótese sustentada, reside no contato humano com animais em criação para consumo humano -, às cadeias de transmissão (PERROTA, 2020), aos efeitos da interrupção produtiva e à janela histórica para que repensemos a forma 
como o metabolismo humano interage com a dinâmica da natureza não humana.

\section{Conclusões}

Com o presente estudo, pudemos verificar como as dimensões de existência humanas podem ser mediatizadas pelo direito sem se manifestar contradições com a crítica ao direito de matriz marxista. Esta busca pelas mais diversas dimensões de vida - que condensamos a partir da chama do Direito à Existência, impulsionados pela sugestão de Daniel Bensaïd - se revela não só em aspectos sociais, consagradores de condições materiais de existência, mas também políticos, impulsionadores da afirmação em luta das classes trabalhadoras e dos setores oprimidos da sociedade.

Ocorre, porém, que este Direito à Existência, tomada a experiência brasileira, se mostrou profundamente atacado no último período, sobretudo depois da cristalização de conquistas políticas no desembocar do processo de redemocratização formal brasileiro. Tanto as dimensões materiais de existência de trabalhadores e trabalhadoras, como as suas perspectivas de autoorganização, se viram tolhidas por paramentos jurídicos e por atos de violência direta.

Estes atos de ofensiva contra as classes trabalhadores e setores oprimidos da sociedade são marcados por uma agenda internacional comum, preventiva e contrarrevolucionária, que se expressa de modo particular - tanto em intensidade como em temporalidade - em nosso país, e se alia a uma dimensão que em momento algum pode ser secundarizada pelos movimentos sociais das mais diversas naturezas: a questão ambiental.

Da mesma sorte que a ofensiva burguesa em busca de ampliação de margens de lucro atenta contra a renda e as condições de vida e militância de quem trabalha, também assim age contra o meio ambiente, cada vez mais promovendo graves violações à natureza, muitas delas irreparáveis dentro da temporalidade da vida humana.

As alternativas postas à crise civilizacional, e em especial à sua dimensão ambiental, entendemos nós e seguindo os ditames do já 
exaustivamente citado Michael Löwy, reclamam necessariamente a transposição da ordem social capitalista, que não comporta remédios ou arremedos, merecendo, também por conta do descaso com o ambiente na promoção de suas ações, ser de uma vez por todas suplantada.

Como intelectuais e militantes nosso papel, ainda que limitado, reclama posicionamento frente a este quadro de coisas. Não basta mais, como aprendemos com Marx em sua Tese XI sobre Feuerbach, interpretar o mundo. E desemboca nosso estudo na imprescindível necessidade de articulação do conjunto dos movimentos sociais - sindicais, estudantis, de luta pela terra, por modos tradicionais de sociabilidade, por cultura, por reconhecimento, contra a carestia, por serviços públicos, por moradia etc - à indispensável tarefa de olhar à questão ambiental não como elemento de ordem menor, mas como marco de suma importância às nossas existências, e que cuja defesa da natureza se faz urgente, tamanha a dimensão da crise civilizacional ora experimentada.

Esta, como todas as crises, abre janelas históricas e bifurcações diante de nós. E sabemos, há remédios para lidar com a barbárie. As perspectivas que se colocam na resistência unitária classista às contrarreformas - sociais, políticas, ambientais - parece ser uma das únicas perspectivas que se assentam como eficazes para, no âmbito nacional, colocar freio à ofensiva burguesa que se move pela retirada de direitos trabalhistas, previdenciários e contra a vida de amplos setores da população. Devem tais lutas e setores em combate, porém, agir em conjunto, e não se deixar levar aos intentos burgueses - por vezes bem revestidos com lustros pós-modernos - de fragmentação na política.

Diz o grande músico Odair Cabeça de Poeta, mentor do Grupo Capote, que "a dor é curta e o nome cumprido". No nosso caso é o contrário que se afigura: a dor é longa e o nome curto. E o nome de nossa dor é capital. Dor de todas e todos que vivem sob o jugo da opressão e exploração. Coloca-se como nossa tarefa imediata e urgente portar-se contra a integralidade de suas ganas expansivas, e isso com a integralidade das forças sociais em movimento. Só desse modo, entendemos, a afirmação da mercadoria - que coloca uma cortina de fumaça à vista que inspirou Trotsky na compreensão de que a vida é bela e deve ser gozada na sua plenitude - possa sucumbir e que possamos nós, também, olhar para essas janelas que se abrem - históricas, fundamentalmente 
- e construir um mundo novo, em que nossos debates sobre direitos, resistências e lutas pela vida ficará apenas no registro do passado.

\section{Referências}

AGUITON, Christophe. BENSAIID, Daniel. Le retour de la question sociale: le renouveau des mouvements sociaux um France. Lausanne: Page Deux, 1997. ANTUNES, Ricardo. O privilégio da servidão. São Paulo: Boitempo, 2018. BARROS, Ilena Felipe. O agronegócio e a atuação da burguesia agrária: considerações da luta de classes no campo. Serv. Soc. Soc., São Paulo, n. 131, p. 175-195, jan./abr. 2018.

BATISTA, Flávio Roberto. SEFERIAN, Gustavo. "Financiamento sindical, direito do trabalho e crise: aproximações empíricas ao tema da funcionalidade do direito do trabalho para o capitalismo." Direito e Práxis, v. 11, n. 4, Rio de Janeiro, no prelo.

. "Terceirização e sindicalismo: reflexões sobre o papel dos sindicatos e suas possibilidades de reação à transição pós-fordista”. In: SERAU JÚNIOR, Marco Aurélio. (Org.). Terceirização: conceito, crítica, reflexos trabalhistas e previdenciários. São Paulo: LTr, 2018.

BENITEZ MARTINS, Carla. Distribuir e punir? Capitalismo dependente brasileiro, racismo estrutural e encarceramento em massa nos governo do Partido dos Trabalhadores (2003-2016). Tese (Doutrado) defendida junto ao programa de pós-graduação em sociologia da Universidade Federal de Goiás, 2018.

BENSAIID, Daniel. Éloge de la politique profane. Paris: Albin Michel, 2008. Les dépossédés: Karl Marx, les voleurs de bois et le droit des pauvres. Paris: La fabrique, 2007.

Moi, la révolution: remembrances d'une bicentenaire indigne.Paris: Gallimard, 1989.

Résistances: essai de taupologie générale. Paris: Fayard, 2001.

. Um monde à changer: mouvements et stratégies. Paris: Textuel, 2003. 
BRASIL DE FATO. Existe alternativa à exploração predatória das mineradoras? Brasília: Brasil de Fato, 2019. Disponível em:

https://www.brasildefato.com.br/2019/02/10/existe-alternativa-a-exploracaopredatoria-das-mineradoras. Acessado em: 23/03/2020.

CÂMARA, João Batista Drummond. Governança ambiental no Brasil: ecos do passado. Revista de sociologia e política, v. 21, n. 46, p.125-146, jun/2013. CARTA CAPITAL. Bolsonaro ameaça: "Vamos varrer do mapa esses bandidos vermelhos”. Publicado em 21/10/2018. Disponível em:

https://www.cartacapital.com.br/politica/ apitalis-ameaca-201cvamosvarrer-do-mapa-esses-bandidos-vermelhos201d/. Acessado em: 20/03/2020. CASTELO BRANCO, Rodrigo. A “questão social” e o social-liberalismo brasileiro: contribuição à crítica da noção do desenvolvimento econômico com equidade. Emancipação, Ponta Grossa, n.8, v. 1, p.21-35, 2008. COMPARATO, Fábio Konder. A afirmação histórica dos direitos humanos. $11^{\mathrm{a}}$ ed. São Paulo: Saraiva, 2017.

COSME, Claudemir Martins. Os governos do PT e os descaminhos com a questão agrária no Brasil: contribuições para um diálogo polêmico, necessário e imprescindível à classe trabalhadora. Revista Pegada, vol. 17 n.1, p.312-346, Julho/2016.

EDELMAN, Bernard. A legalização da classe operária. Trad. Marcus Orione (coord.) et alii. São Paulo: Boitempo, 2016.

FUKUYAMA, Francis. O fim da história e o último homem. Trad. Aulyde Soares Rodrigues. Rio de Janeiro: Rocco, 1992.

GREENPEACE. "Assassinatos de lideranças e violência no campo crescem em 2019. Disponível em: https://www.greenpeace.org/brasil/blog/assassinatos-deliderancas-indigenas-camponesas-e-violencia-no-campo-crescem-em-2019/. Acessado em 17 de abril de 2020.

HARVEY, David. A condição pós-moderna: Uma pesquisa sobre as origens da mudança cultural. Trad. Adail Ubirajara Sobral e Maria Stela Gonçalves. $\mathbf{2 5}^{\mathrm{a}}$ ed., São Paulo: Loyola, 2014.

KEUCHEYAN, Razmig. La nature est um champ de bataille. Paris: La decouverte, 2018 


\section{LÖWY, Michael. A política do desenvolvimento desigual e combinado:}

a teoria da revolução permanente. Trad. Luiz Gustavo Soares. São

Paulo: Sunderman, 2015 .

Crise ecológica, crise capitalista, crise de civilização: a alternativa ecossocialista.

Caderno CRH, Salvador, v. 26, 67, p. 79-86, Jan./Abr.2013.

Daniel Bensaïd: um marxisme de la bifurcation. Mediapart. Publicado

em 23/o2/2020. Diponível em: https://blogs.mediapart.fr/michael-

lowy/blog/230220/ apita-bensaid-um-marxisme-de-la-bifurcation

LUKÁCS, Georg. História e Consciência de classe: estudos sobre a dialética marxista. Trad. Rodnei Nascimento. São Paulo: Martins Fontes, 2003.

MANDEL, Ernest. $\mathbf{O}$ apitalism tardio. Trad. Carlos Eduardo Silveira

Matos, Regis de Castro Andrade e Dinah de Abreu Azevedo. São Paulo: Abril

Cultural, 1982.

MARINI, Ruy Mauro. Dialética da Dependência. Petrópolis: Vozes/ Buenos Aires: Clacso, 2000.

MARX, Karl. O Capital: crítica da economia política. Livro I: o processo de produção do capital. Trad. Rubens Enderle. São Paulo: Boitempo, 2013.

Os despossuídos: debates sobre a lei referente ao furto de madeira.

Trad. Nélio Schneider. São Paulo: Boitempo, 2017.

O 18 de brumário de Luis Bonaparte. Trad. Nélio Schneider. São

Paulo: Boitempo, 2011.

ENGELS, Friedrich. Manifesto Comunista, Trad. Álvaro Pina. São

Paulo: Boitempo, 2010.

MASCARO, Alysson Leandro. Estado e forma política. São Paulo: Boitempo, 2013 .

MBEMBE, Achille. Necropolítica. 3. Ed. Trad. Renata Santini. São Paulo: n-1, 2018.

MILANEZ, Bruno. SANTOS, Rodrigo Salles Pereira de. Neoextrativismo no

Brasil? Uma análise da proposta do novo marco legal da mineração. R. Pós Ci.

Soc. V.10, n.19, p. 119-148, jan/jun. 2013.

NUNES, Edison. Movimentos populares na transição inconclusa. Lua Nova, n. 13 , set/1987, p. 87-94. 
OLIVEIRA, Francisco de. "Hegemonia às avessas”. In: OLIVEIRA, Francisco de; BRAGA, Ruy. RIZEK, Cibele. Hegemonia às avessas: economia, política e cultura na era da servidão financeira. São Paulo: Boitempo, 2010.

PACHUKANIS, Evgeni. A teoria geral do direito e o marxismo e ensaios escolhidos (1921-1929). Coord.: Marcus Orione. Trad. Lucas Simone. São Paulo: Sundermann, 2017.

PERROTA, Ana Paula. “Serpentes, morcegos, pangolins e 'mercados úmidos' chineses: Uma crítica da construção de vilões epidêmicos no combate à Covid19”. In: DILEMAS: Revista de Estudos de Conflito e Controle Social - Rio de Janeiro - Reflexões na Pandemia 2020, p. 1-6.

SARTORI, Vitor Bartoletti. Direito, Política e Reconhecimento: apontamentos sobre Karl Marx e a crítica ao direito. Revista da Faculdade de Direito UFPR. Curitiba, v. 61, n. 2, maio/ago, 2016, p. 203-233.

SEFERIAN Scheffer Machado, Gustavo. Direito do Trabalho como barricada: sobre o uso tático da proteção jurídica dos trabalhadores. Tese (doutorado) em Direito. Universidade de São Paulo, 2017. . “'Hoje és nevoeiro...': linhas sobre o conteúdo e sentido do trabalho escravo contemporâneo.” REVISTA VIDERE, v. 10, p. 263-282, 2018. SOUTO MAIOR, Jorge Luiz. Direito do trabalho como instrumento de justiça social. São Paulo: LTr, 2000.

TANURO, Daniel. L'impossible capitalisme vert. Paris: La découverte, 2012.

TAO, Matheus Itiro de Castro. AQUINO, Dayani Cris de. O hiato entre o elemento histórico-moral do valor da força de trabalho e a remuneração recebida: o endividamento das famílias. Anais do Colóquio Internacional Marx e o Marxismo 2019. Marxismo sem tabus - enfrentando opressões. Disponível em: www.niepmarx.blog.br/MM2019/Trabalhos\%20aprovados/MC48/MC481.pdf . Acessado em: 20/03/2020.

TEIXEIRA, Andréia Maria de Paula. Reforma e contra-reforma na Previdência Social no Brasil de hoje. Katálysis, n. 5, jul/dez 2001, p. 49-62. 
THE GUARDIAN. “The defenders: 98 environmental defenders have been killed so far in 2017”. Disponível em: https://www.theguardian.com/environment/nginteractive/2017/jul/13/the-defenders-tracker. Acesso em: 31/o7 /2017. THOMPSON, Edward P. A formação da classe operária: a árvore da liberdade, Vol I, Trad. Denise Bottmann. Rio de Janeiro: Paz e Terra, 1987. TROTSKY, Leon. “Balanço e perspectivas”. In: A teoria da revolução permanente. São Paulo: Sundermann, 2011.

História da Revolução Russa. T. I, Trad. Diego de Siqueira. São Paulo: Sundermann, 2007.

A moral deles e a nossa. Trad. M. Resende, Lisboa: Antídoto, 1979. 